\title{
Introducing Digital Mammography in a Resource Constrained Setting: Spectrum of Imaging Findings and Diagnostic Value in Ado-Ekiti, South Western Nigeria
}

\author{
Olufunso Simisola Aduayi ${ }^{1,}$, , Ganiyu Olusola Akanbi ${ }^{1}$, Victor Adovi Aduayi ${ }^{2}$ \\ ${ }^{1}$ Department of Radiology, College of Medicine, Ekiti State University, Ado-Ekiti, Nigeria \\ ${ }^{2}$ Department of Epidemiology and Community Health, College of Medicine, Ekiti State University, Ado-Ekiti, Nigeria \\ Email address: \\ faduayi@gmail.com (O. S. Aduayi) \\ ${ }^{*}$ Corresponding author
}

\section{To cite this article:}

Olufunso Simisola Aduayi, Ganiyu Olusola Akanbi, Victor Adovi Aduayi. Introducing Digital Mammography in a Resource Constrained Setting: Spectrum of Imaging Findings and Diagnostic Value in Ado-Ekiti, South Western Nigeria. International Journal of Medical Imaging. Vol. 4, No. 2, 2016, pp. 7-11. doi: 10.11648/j.ijmi.20160402.11

Received: April 22, 2016; Accepted: May 3, 2016; Published: May 13, 2016

\begin{abstract}
Early diagnosis and treatment achieved through Mammographic screening plays a key role in the reduction of breast related morbidities and mortalities in middle and low income countries. This study highlights the spectrum of digital mammography findings in a tertiary health institution in Ado-Ekiti, South western Nigeria. A cross-sectional descriptive study of clients who presented for digital mammography at a newly equipped hospital was conducted within a year. The mammograms were reviewed by two radiologists and overall imaging findings were classified using the American College of Radiology Breast Imaging Reporting and Data System (ACR-BIRADS). Data analysis was done using SPSS version 20.0. A

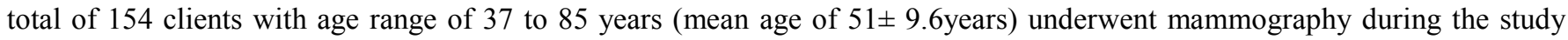
period. There was one male and 153 females out of which 69(45.1\%) were postmenopausal while 84(54.9\%) were premenopausal. Major clinical indications for mammography included routine breast cancer screening $(\mathrm{N}=59,38.3 \%)$, breast lump ( $\mathrm{N}=43,27.9 \%)$ and breast pain $(\mathrm{N}=34,22.1 \%)$. Mammograms were normal in 37(24.0\%), inconclusive in 51(33.1\%) and abnormal in 66(42.9\%) clients. Abnormal mammographic findings included various forms of calcifications $(\mathrm{N}=56$, $36.4 \%)$, breast opacities/masses $(\mathrm{N}=42,27.3 \%)$, axillary lymphadenopathy $(\mathrm{N}=14,9.0 \%)$, focal glandular asymmetry $(\mathrm{N}=10$, $6.5 \%)$ and architectural distortion $(\mathrm{N}=6,3.9 \%)$. About 55(35.7\%) patients underwent additional imaging with ultrasonography, out of which $32(58.2 \%$ ) had positive sonographic findings. The use of ultrasonography for additional imaging in cases of inconclusive mammograms improves the diagnostic yield. A greater proportion of the clients had mammography done for diagnostic reasons rather than screening purposes. Hence there is the need for increased awareness of screening mammography among the women in resource constrained settings.
\end{abstract}

Keywords: Mammography, Women, Digital Imaging, Breast Cancer

\section{Introduction}

Radiological examination of the breast is established as an essential part of the modern multidisciplinary approach to effective investigation and management of breast diseases [1] Breast imaging has evolved with technological advancement over the years. Magnetic resonance imaging (MRI), Digital mammography, breast tomosynthesis, automated breast ultrasound scan, and shear wave elastography play key roles in breast imaging in the developed nations. [2-5] On the contrary, in the developing nations such sophisticated imaging equipment is not readily available due to resource constraints. Studies have reported that benign breast diseases are commoner than their malignant counterpart worldwide. [6-8] Mammography is an important radiological imaging modality for screening and diagnostic appraisal of breast diseases. Early diagnosis and treatment achieved through Mammographic screening plays a key role in the reduction of breast related morbidities and mortalities in middle and low 
income countries. However, mammography is not recommended for routine use among women below the age of 40 years [9]; also the sensitivity is reduced in those with mammographically dense breasts $[5,10]$. In such instances conventional breast ultrasound is utilized as an alternative or adjunct imaging modality due to its availability. Digital mammography has documented advantage over the analogue (film screen) mammography in terms of the image quality and diagnostic accuracy $[11,12]$ but it is currently available in few centers in Nigeria. This study highlights the spectrum of imaging findings and the role of digital mammography in the diagnostic evaluation of breast diseases at a newly equipped tertiary health institution in south western Nigeria.

\section{Subjects and Methods}

A cross-sectional descriptive study was conducted from February 2014 to January 2015 at Ekiti State University Teaching Hospital, Ado-Ekiti, South western Nigeria. The study was approved by the hospital ethics and research committee. The study population consisted of consecutive patients that came for screening and diagnostic mammography in the breast imaging unit of our health facility.

Relevant baseline information was obtained and procedure was explained to the client. Mammographic images of the breasts were acquired with a General Electric (GE) digital mammogram machine using two standard views \{CranioCaudal (CC) and Mediolateral Oblique (MLO)\}. Additional views such as spot compression and magnification views were added where necessary. The mammograms were evaluated by two trained radiologists at the computer workstation. The mammographic breast density pattern was noted. Mammographic abnormalities such as circumscribed opacities, calcifications, architectural distortion, parenchymal asymmetry and axillary lymphadenopathy were also documented when present. Mammographic breast density pattern were classified and overall imaging findings were categorized using the American College of Radiology BIRADS classification. Mammographic breast density pattern classification is as follows: BIRADS 1: Almost entirely fatty pattern; BIRADS 2: Scattered fibroglandular pattern; BIRADS 3: Heterogeneously dense pattern and BIRADS 4: Extremely dense pattern.

The assessment categories of mammographic findings are as follows: BIRADS 0: Inconclusive study; BIRADS 1: Normal study, BIRADS 2: Benign findings, BIRADS 3: Probably benign findings; BIRADS 4: Suspicious lesion, BIRADS 5: Highly suspicious lesion and BIRADS 6: Biopsy proven malignancy.

Breast ultrasound scan was done for patients that needed additional imaging evaluation using the linear $7.5-10 \mathrm{MHz}$ transducer of a Mindray DCN-2 ultrasound scanner. The data was collated and analyzed using the Statistical Package for Social Sciences (SPSS) version 20 software. Analysis was done on a univariate level with socio-demographic and other relevant variables presented in frequencies and proportions using tables.

\section{Results}

Between February 2014 and January 2015 a total of 154 digital mammograms were done at our centre. The age range of participants was 37 to 85 years with a mean age of $51 \pm$ 9.6years. Majority were within age group 40 - 49 years $(\mathrm{N}=78,50.6 \%)$ while participants aged 80 years and above were few (Table 1). There were 153 females and one male. Among the females, 69(45.1\%) were postmenopausal while $84(54.9 \%)$ were premenopausal.

Table 1. Age distribution of patients.

\begin{tabular}{lll}
\hline Age group & Frequency & Percent $(\%)$ \\
\hline$<40$ & 4 & 2.6 \\
$40-49$ & 78 & 50.6 \\
$50-59$ & 43 & 27.9 \\
$60-69$ & 22 & 14.3 \\
$70-79$ & 4 & 2.6 \\
$>80$ & 3 & 1.9 \\
Total & 154 & 100.0 \\
\hline
\end{tabular}

About 59 (38.3\%) participants presented for routine mammography screening for breast cancer while the remaining 95(61.7\%) presented for diagnostic mammography on account of various breast related complaints (Table 2). The most common clinical indication for diagnostic mammography was breast lump ( $=43,27.9 \%)$, followed by breast pain $(\mathrm{N}=34,22.1 \%)$.

Table 2. Clinical Indications for mammography.

\begin{tabular}{lll}
\hline $\begin{array}{l}\text { Clinical Indications for } \\
\text { mammography }\end{array}$ & Frequency $(\mathbf{N = 1 5 4 )}$ & Percentages \\
\hline Routine check & 59 & 38.3 \\
Breast lump & 43 & 27.9 \\
Breast pain & 34 & 22.1 \\
Post mastectomy & 5 & 3.2 \\
Nipple discharge & 4 & 2.6 \\
Axillary lymphadenopathy & 4 & 2.6 \\
Post excisional biopsy & 2 & 1.3 \\
Breast lump and nipple discharge & 2 & 1.3 \\
Nipple ulceration & 1 & 0.6 \\
\hline
\end{tabular}

Table 3. Menstrual status and breast parenchymal pattern of the patients.

\begin{tabular}{lll}
\hline & Frequency $(\mathbf{N = 1 5 4 )}$ & percentage \\
\hline $\begin{array}{l}\text { Breast parenchymal density } \\
\text { pattern }\end{array}$ & & \\
$\begin{array}{l}\text { (BIRADS 1)Almost entirely fatty } \\
\text { (BIRADS 2) Scattered }\end{array}$ & 54 & 35.1 \\
$\begin{array}{l}\text { fibroglandular tissue } \\
\text { (BIRADS 3) Heterogeneously }\end{array}$ & 72 & 11.0 \\
$\begin{array}{l}\text { dense } \\
\text { (BIRADS 4) Extremely dense }\end{array}$ & 11 & 46.8 \\
$\begin{array}{l}\text { Menstrual status } \\
\text { Postmenopausal }\end{array}$ & 69 & 7.1 \\
$\begin{array}{l}\text { Premenopausal } \\
\text { Not applicable (Male) }\end{array}$ & 84 & 44.8 \\
\hline
\end{tabular}

The predominant breast parenchymal pattern (Table 3) was the heterogeneously dense (BIRADS 3 ) pattern $(\mathrm{N}=72$, $46.8 \%$ ) and this was closely followed by the almost entirely fatty pattern $(\mathrm{N}=54,35.1 \%)$. Mammograms were normal in $37(24.0 \%)$, inconclusive in 51(33.1\%) and abnormal findings 
were seen in 66(42.9\%) clients. Various forms of calcifications (micro-calcifications, macro-calcifications, parasitic, arterial and ductal calcifications) accounted for the highest number of abnormal mammographic findings $(\mathrm{N}=56$, $36.4 \%$ ) followed by circumscribed breast opacities/masses $(\mathrm{N}=42,27.3 \%)$. Other abnormal mammographic findings included axillary lymphadenopathy $(\mathrm{N}=14,9.0 \%)$, focal glandular asymmetry $(\mathrm{N}=10,6.5 \%)$ and architectural distortion $(\mathrm{N}=6,3.9 \%)$ (Table 4$)$.

Table 4. Abnormal Mammographic findings.

\begin{tabular}{llll}
\hline Abnormal findings & Right breast & Left breast & Bilateral \\
\hline Calcifications & & & \\
Macro-calcifications & $7(4.5)$ & $7(4.5)$ & $8(5.2)$ \\
Micro-calcifications & $5(3.2)$ & $6(2.5)$ & $3(1.9)$ \\
Parasitic calcifications & $5(3.2)$ & $7(4.5)$ & $3(1.9)$ \\
Arterial calcifications & --- & $2(1.3)$ & $2(1.3)$ \\
Ductal calcifications & $1(0.6)$ & --- & --- \\
Breast opacity /mass & & & \\
Irregular/spiculated /angular & $11(7.1)$ & $13(8.4)$ & $2(1.3)$ \\
margins & $5(3.2)$ & $8(5.2)$ & $3(1.9)$ \\
Rounded/well defined margins & $9(5.8)$ & $4(2.6)$ & $1(0.6)$ \\
Axillary lymphadenopathy & $2(1.3)$ & $7(4.5)$ & $1(0.6)$ \\
Focal glandular asymmetry & $2(1.3)$ & $4(2.6)$ & --- \\
Architectural distortion & & & \\
\hline
\end{tabular}

The final BIRADS category based on overall mammographic features is shown in Table 5; BIRADS 0 (Inconclusive, requires additional imaging) was seen in $51(33.1 \%)$ cases followed by BIRADS 1 (Normal study) in $37(24 \%)$ cases. (Table 5)

Table 5. Mammographic diagnosis and BIRADS classification.

\begin{tabular}{lll}
\hline BIRADS Category & Frequency $(\mathbf{N = 1 5 4 )}$ & Percentage (\%) \\
\hline 0 (Inconclusive study) & 51 & 33.1 \\
1 (Normal study) & 37 & 24.0 \\
2 (Benign findings) & 24 & 15.6 \\
3 (Probably benign findings) & 12 & 7.8 \\
4 (Suspicious findings) & 25 & 16.2 \\
5 (Highly suspicious findings) & 5 & 3.2 \\
\hline
\end{tabular}

About 55(35.7\%) patients had additional imaging using breast ultrasonography, out of which $23(41.8 \%)$ had had normal findings. The most common abnormal ultrasonography finding among the remaining 32 (58.2\%) patients was breast cyst/fibrocystic disease (Table 6).

Table 6. Ultrasonography findings among patients who had additional imaging done.

\begin{tabular}{ll|l}
\hline Ultrasound findings & Frequency $(\mathbf{N}=\mathbf{5 5})$ & Percentage \\
\hline Breast cysts/fibrocystic disease & 12 & 21.8 \\
Suspicious breast mass & 7 & 12.7 \\
Ductal ectasia & 6 & 10.9 \\
Mitotic breast mass & 3 & 5.5 \\
Intraductal masses & 2 & 3.6 \\
Fibroadenoma & 1 & 1.8 \\
Axillary lymphadenopathy & 6 & 10.9 \\
Normal & 23 & 41.8 \\
\hline
\end{tabular}

\section{Discussion}

Breast imaging with mammography is still in its first decade in most parts of Nigeria. Some studies have reported on the mammographic findings in different parts of the country $[1,2,13-19]$. About half of the participants in this study were within the age group 40-49 years. Some studies within $[2,18]$ and outside Nigeria [20,21] also revealed that a greater percentage of women presenting for mammography fall within this age group. This is may be due to the fact that baseline routine mammographic evaluation commences by the fifth decade of life [2].

Mammography is mainly a women's imaging procedure, notwithstanding, a male client had mammographic evaluation in this study on account of breast related complaints. Similarly, few males were reported to have undergone diagnostic mammography in some parts of Nigeria $[2,14]$ in contrast to most other studies that had only female participants $[1,13,16,17,19]$. This underscores the fact that breast diseases are not exclusive to females, though the incidence of breast cancer in males is very low.

The burden of breast cancer is significant in developing countries. Reasons adduced for that include poor knowledge of breast cancer risk factors, signs and symptoms [22, 23]; lack of awareness coupled with poor attitude to preventive practice [24-28] and late presentation at an advanced stage of the disease [29, 30]. Lack of effective national screening programmes against a backdrop of poor socioeconomic status also contribute to the breast cancer burden in resource constrained settings. Within the first year of utilization of mammography at our newly equipped centre, majority of the clients presented for mammography on account of various breast related complaints while only $38.3 \%$ presented for routine breast cancer screening. A similar pattern was observed by Danfulani et al [1] in the Northern part of Nigeria. This reflects the need for awareness creation among women in our environment in order to encourage participation in screening mammography. Early detection will engender a much desired reduction in breast cancer related morbidities and mortalities which is often associated with late presentation in the developing nations. Breast lumps accounted for the highest clinical indication for diagnostic mammography followed by breast pain. Comparing with previous local studies, this is similar to findings by Akande et al [2] in Ilorin and Akinola et al [17] in Lagos but in contrast to findings by Danfulani et al [1] in Sokoto and Ebubedike et al [19] in Anambra where breast pain was the most common indication for diagnostic mammography.

Mammographic abnormalities were detected in $42.9 \%$ of the study participants. Most of the patients who presented for diagnostic mammography were found to have more of benign breast diseases than breast cancers in keeping with findings in other parts of the country $[1,2,17,19]$ The predominant abnormal mammographic findings were breast calcifications (macro-calcifications, micro-calcifications, parasitic, arterial and ductal calcifications) and breast masses /circumscribed opacities. Calcifications can be associated with benign or 
malignant lesions. Majority of the calcifications were benign macrocalcifications in keeping with some other studies done in Nigeria [19]. About 14(9.1\%) of the participants had mammographically detected suspicious microcalcifications which often raises concerns about early features of breast cancer. Mammography is highly sensitive for early detection of cancer and remains the goal standard in breast cancer screening [31]. However, mammographic sensitivity in cancer detection is reduced in dense breasts which is a reflection of the amount of radiographic dense epithelium and stroma in the breast [32] Digital mammography improves the detection of cancer in younger women but is associated with higher costs compared to film mammography. In a study of over 40,000 women, the accuracy of digital mammography was significantly higher than that of film mammography for women under 50 years old, pre- and peri-menopausal women and those with heterogeneously dense or extremely dense breasts on mammography [12]. The predominant mammographic breast parenchymal density pattern in this study was the heterogeneously dense $(46.8 \%)$ pattern (BIRADS 3 ) this was closely followed by the almost entirely fatty breast (35.1\%) parenchymal pattern (BIRADS 1). This is similar to the predominant breast parenchymal density pattern in Ebubedike et al [19] study. On the contrary, Pak et al [33], Akinola et al [17] and Akande et al [2] studies had predominant scattered fibroglandular pattern (BIRADS 2) while Obajimi et al [34] had almost entirely fatty pattern (BIRADS 1) predominance. Heterogeneously dense and extremely dense breast parenchymal patterns can obscure a lesion and thus reduce the sensitivity of the mammographic examination [5]. Also, mammographic breast density has been linked with increased breast cancer risk [10]. In such instances, additional imaging is recommended and conventional breast ultrasonography is the readily available complementary imaging modality at our centre. About $58.2 \%$ of the clients in this study who had additional imaging with ultrasonography done on account of inconclusive mammograms (BIRADS 0) had positive findings which were mainly breast cysts/fibrocystic disease. This shows that the use of conventional ultrasonography in patients with inconclusive mammograms improves the radiodiagnostic yield in resource limited settings where other sophisticated breast imaging equipment is not readily available. Breast masses can be subjected to further diagnostic evaluations to determine the nature of the lesion. An ultrasound-guided fine needle aspiration and cytology (FNAC), or histology following core needle biopsy or surgical biopsy will usually confirm the diagnosis of the breast lesion [35]. Further studies correlating the digital mammography features of circumscribed breast opacities with fine needle aspiration cytology and or histology findings can be done in our environment.

\section{Conclusion}

A greater proportion of the patients in this study underwent mammography on account of various breast related complaints as opposed to routine screening for breast cancer. Hence there is the need for increased awareness of screening mammography among the women in resource constrained settings. The use of ultrasonography for additional imaging in cases of inconclusive mammograms improves the diagnostic yield and should be recommended in settings where more sophisticated breast imaging equipment is not available.

\section{References}

[1] Danfulani M: Pattern of mammographic findings in Sokoto, Nigeria. Asian Journal of Medical Sciences (E-ISSN 20910576; P-ISSN 2467-9100) 2014, 5 (4): 79-83.

[2] Akande HJ, Olafimihan BB, Oyinloye OI: A five year audit of mammography in a tertiary hospital, North Central Nigeria. Nigerian medical journal: journal of the Nigeria Medical Association 2015, 56 (3): 213.

[3] Fleury EdFC: The importance of breast elastography added to the BI-RADS ${ }^{\circledR}$ lexicon classification. Revista da Associação Médica Brasileira 2015, 61 (4): 313-316.

[4] Li D-D, Xu H-X, Guo L-H, Bo X-W, Li X-L, Wu R, Xu J-M, Zhang Y-F, Zhang K: Combination of two-dimensional shear wave elastography with ultrasound breast imaging reporting and data system in the diagnosis of breast lesions: a new method to increase the diagnostic performance. European radiology 2015: 1-11.

[5] Lee WK, Chung J, Cha E-S, Lee JE, Kim JH: Digital breast tomosynthesis and breast ultrasound: Additional roles in dense breasts with category 0 at conventional digital mammography. European journal of radiology 2016, 85 (1): 291-296.

[6] Adesunkanmi A, Agbakwuru E: Benign breast disease at Wesley Guild Hospital, Ilesha, Nigeria. West African journal of medicine 2000, 20 (2): 146-151.

[7] Irabor D, Okolo C: An audit of 149 consecutive breast biopsies in Ibadan, Nigeria. Pakistan Journal of Medical Sciences 2008, 24 (2): 257.

[8] Malik G, Waqar F, Buledi GQ: Sonomammography for evaluation of solid breast masses in young patients. J Ayub Med Coll Abbottabad 2006, 18 (2): 34-37.

[9] Lee J, Gordon PB, Whitman GJ: "Do Unto Others as You Would Have Them Do Unto You": Breast Imagers' Perspectives Regarding Screening Mammography for Others and for Themselves-Do They Practice What They Preach? American Journal of Roentgenology 2015, 204 (6): 13361344.

[10] Butler RS: Invited Commentary: The Breast Density Dilemma-Challenges, Lessons, and Future Directions. Radiographics 2015, 35 (2): 324-326.

[11] Glynn CG, Farria DM, Monsees BS, Salcman JT, Wiele KN, Hildebolt CF: Effect of transition to digital mammography on clinical outcomes. Radiology 2011, 260 (3): 664-670.

[12] Pisano ED, Gatsonis C, Hendrick E, Yaffe M, Baum JK, Acharyya S, Conant EF, Fajardo LL, Bassett L, D'Orsi C: Diagnostic performance of digital versus film mammography for breast-cancer screening. New England Journal of Medicine 2005, 353 (17): 1773-1783. 
[13] Adeniji-Sofoluwe AT, Obajimi MO, Olusunmade D: Mammographic calcifications in women in Ibadan, SouthWest Nigeria: A seven years review. West African Journal of Radiology 2015, 22 (2): 76.

[14] Ikpeme A, Akintomide A, Inah G, Oku A: Breast Evaluation Findings in Calabar, Nigeria. Macedonian Journal of Medical Sciences 2014, 7 (4): 650-654.

[15] Akande HJ, Oyinloye OI, Olafimihan BB: Radiological findings of breast cancer screening in a newly equipped centre. International Journal of Medicine and Medical Sciences 2011, 3 (9): 294-298.

[16] Adeyomoye A, Awosanya G, Adesanya A, Anunobi C, Osibogun A: Medical audit of diagnostic mammographic examination at the lagos university teaching hospital (luth), Nigeria. The Nigerian postgraduate medical journal 2009, 16 (1): 25-30.

[17] Akinola R, Akinola O, Shittu L, Balogun B, Tayo A: Appraisal of mammography in Nigerian Women in a new Teaching Hospital. Breast 2007, 54: 18.

[18] Obajimi M, Adeniji-Sofoluwe A, Oluwasola A, Adedokun B, Mosuro O, Adeoye A, Ntekim N, Soyemi T, Osofundiya O, Bassey O: Screening mammography in Ibadan: Our experience. Nigerian Journal of Basic and Clinical Sciences 2015, 12 (2): 74.

[19] Ebubedike UR, Umeh EO, Anyanwu SN, Ukah CO, Ikegwuonu NC: Pattern of mammography findings among symptomatic females referred for diagnostic mammography at a Tertiary Center in South-East Nigeria. West African Journal of Radiology 2016, 23 (1): 23.

[20] Ohlinger R, Heyer H, Thomas A, Paepke S, Warm H, Klug U, Frese H, Schulz K, Schimming A, Schwesinger G: Nonpalpable breast lesions in asymptomatic women: diagnostic value of initial ultrasonography and comparison with mammography. Anticancer research 2006, 26 (5B): 39433955.

[21] Elsie K, Gonzaga M, Francis B, Michael K, Rebecca N, Rosemary B, Zeridah M: Current knowledge, attitudes and practices of women on breast cancer and mammography at Mulago Hospital. Pan African Medical Journal 2010, 5 (1).

[22] Aduayi VA, Aduayi OS, Onayade A, Esimai OA: A Community Based Rural-Urban Comparison of Knowledge and Perception of Women towards Breast Cancer in South Western Nigeria. International Journal of Health Sciences and Research (IJHSR) 2016, 6 (4): 26-32.

[23] Omotara B, Yahya S, Amodu M, Bimba J: Awareness, attitude and practice of rural women regarding breast cancer in Northeast Nigeria. Journal of Community Medicine \& Health Education 2012, 2012.

[24] Aduayi VA, Onayade AA, Aduayi OS, Ijadunola MY: Willingness to accept preventive bilateral mastectomy among women in rural and urban communities in South-Western Nigeria. International Journal of Community Medicine and Public Health 2015, 2 (2): 86-93.
[25] Amoran O, Toyobo T, Fatugase O: Breast Cancer Screening Awareness and Practice among Women in Sagamu Local Government Area, South-Western Nigeria: A Community Based Study. British Journal of Applied Science \& Technology 2014, 4 (16): 2320.

[26] Adegbenro C, Ajala A, Ajayi O, Ajayi T, Ajayi O, Ajewole A, Oyedeji A: Awareness of Breast Cancer and Practice of Breast Self-Examination among Rural Women in Ife-North Local Government Area, Osun State, South-West Nigeria. Journal of Community Medicine and Primary Health Care 2015, 26 (1): 76-87.

[27] Obajimi MO, Ajayi IO, Oluwasola AO, Adedokun BO, Adeniji-Sofoluwe AT, Mosuro OA, Akingbola TS, Bassey OS, Umeh E, Soyemi TO: Level of awareness of mammography among women attending outpatient clinics in a teaching hospital in Ibadan, South-West Nigeria. BMC public health 2013, 13 (1): 1 .

[28] Akinola R, Wright K, Osunfidiya O, Orogbemi O, Akinola O: Mammography and mammographic screening: are female patients at a teaching hospital in Lagos, Nigeria, aware of these procedures? Diagnostic and Interventional Radiology 2011, 17 (2): 125.

[29] Pace LE, Mpunga T, Hategekimana V, Dusengimana J-MV, Habineza H, Bigirimana JB, Mutumbira C, Mpanumusingo E, Ngiruwera JP, Tapela N: Delays in breast cancer presentation and diagnosis at two rural cancer referral centers in Rwanda. The oncologist 2015, 20 (7): 780-788.

[30] Teh Y-C, Tan G-H, Taib NA, Rahmat K, Westerhout CJ, Fadzli F, See M-H, Jamaris S, Yip C-H: Opportunistic mammography screening provides effective detection rates in a limited resource healthcare system. BMC cancer 2015, 15 (1): 1 .

[31] Nandi R, Nandi AK, Rangayyan RM, Scutt D: Classification of breast masses in mammograms using genetic programming and feature selection. Medical and biological engineering and computing 2006, 44 (8): 683-694.

[32] Heng D, Gao F, Jong R, Fishell E, Yaffe M, Martin L, Li T, Stone J, Sun L, Hopper J: Risk factors for breast cancer associated with mammographic features in Singaporean Chinese women. Cancer Epidemiology Biomarkers \& Prevention 2004, 13 (11): 1751-1758.

[33] Pak-art P, Bunjunwetwat D, Vajragupta L, Amornrattanapaijit W, Vajarapongse K, Sampatanukul P, Chatamra K: Abnormal findings in breast imaging: a hospital-based survey in 4264 Thai women. Journal of the Medical Association of Thailand= Chotmaihet thangphaet 2004, 87: S179-184.

[34] Obajimi M, Adeniji-Sofoluwe A, Oluwasola A, Adedokun B, Soyemi T, Olopade F, Newstead G: Mammographic breast pattern in Nigerian women in Ibadan, Nigeria. Breast disease 2011, 33 (1): 9-15.

[35] Anyikam A, Nzegwu MA, Ozumba BC, Okoye I, Olusina DB: Benign breast lesions in Eastern Nigeria. Saudi medical journal 2008, 29 (2): 241-244. 